\title{
AVALIAÇȮES DE LINGUA PORTUGUESA NO CONTEXTO DO PACTO NACIONAL PELA ALFABETIZAÇÃO NA IDADE CERTA EM MATO GROSSO
}

\author{
Ângela Rita Christofolo de Mello \\ Albina Pereira de Pinho Silva
}

\begin{abstract}
Resumo: $\mathrm{O}$ artigo analisa as avaliações de Língua Portuguesa inseridas no Simec/SisPacto pelos professores de Mato Grosso, no início e no final de 2014. As avaliações se referem aos onze direitos de aprendizagem de Língua Portuguesa e nos foram concedidas pela coordenação geral do PNAIC em Mato Grosso em abril de 2015. Essas foram sistematizadas em quadros e demonstram como os alfabetizandos se encontravam no início e no final de 2014, em relação a cada um dos direitos de aprendizagem. A análise ancorou-se na abordagem qualitativa e investigou se houve um avanço na apropriação do conhecimento dos alfabetizandos e uma correlação entre os direitos de aprendizagem. As fragilidades do processo de alfabetização foram apontadas e ajustes necessários para a superação dessas foram sugeridos.
\end{abstract}

Palavras-chave: Alfabetização. Avaliação. Mato Grosso.

Introdução

No ano de 2013, o Ministério da Educação (MEC) assumiu um compromisso formal com os Governos distrital, estaduais e municipais com o objetivo de alfabetizar todas as crianças brasileiras até aos oito anos de idade, quando finda o 1. ciclo da Educação Básica. Nestes termos, instituiu-se o Pacto Nacional pela Alfabetização na Idade Certa (PNAIC) em todos os estados brasileiros. Este compromisso foi justificado porque os indicadores sociais disponibilizados por meio da realização de avaliações externas pelo Instituto Nacional de Estudos e Pesquisas Educacionais Anísio Teixeira (INEP), nos últimos anos, informaram que, no Brasil, muitas crianças concluem o ciclo da alfabetização sem estarem plenamente alfabetizadas. "Assim, este Pacto surge como uma luta para garantir o direito de alfabetização plena" (BRASIL, 2012, p. 05) a todas as crianças nos três primeiros anos de escolarização.

Em atenção ao compromisso firmado, um conjunto de ações integradas foi organizado, a exemplo da oferta de formação aos professores alfabetizadores. Vinculada às atividades de formação ofertada a todos os professores que atuavam no ciclo da alfabetização (1ํ, 2ํ e 3ำ anos), incluíramse as avaliações da aprendizagem, a gestão, o controle social e a mobilização. Todavia, fundamentado em uma concepção de educação progressista, o PNAIC considera a avaliação como "uma ação intencional que se dá de modo multidirecional" (BRASIL, 2012a, p. 5), ou seja, uma ação que envolve várias pessoas e instâncias, pois "busca um sistema integrado de co-avaliação, no qual 
docentes, discentes e equipes de profissionais da escola e de outros sistemas avaliam e são avaliados" (Idem).

Assim, ao se referir às avaliações processuais, o PNAIC orienta que essas podem e devem ser realizadas pelos professores continuadamente. Com esta compreensão, o Programa disponibilizou o Sistema Integrado de Monitoramento Execução e Controle do Ministério da Educação (Simec) que alimentou o Sistema de Monitoramento do Curso de Formação voltado aos Orientadores de Estudo vinculados ao Pacto Nacional pela Alfabetização na Idade Certa (SisPacto). No Simec/Sispacto os professores alfabetizadores inseriram, em 2014, os dados resultantes dessas avaliações no início e no final do ano letivo, com a intenção de possibilitar o acompanhamento e os ajustes necessários no desenvolvimento da aprendizagem de cada alfabetizando pelos seus professores e gestores.

Trabalhamos com os dados disponibilizados nesses sistemas para analisar a progressão da apropriação dos direitos de aprendizagem em Língua Portuguesa, das crianças matriculadas no ciclo da alfabetização no ano de 2014 em Mato Grosso. Desse modo, o desenvolvimento dessa investigação pautou-se nessas indagações: os dados inseridos no Simec/SisPacto pelos professores alfabetizadores, no início e no final do ano de 2014 , denotaram progressão na apropriação do SEA? Houve uma correlação na apropriação do SEA entre um e outro direito de aprendizagem? As análises dessas avaliações informaram as fragilidades do processo de alfabetização e indicaram ajustes necessários para a sua superação?

1 Procedimentos Metodológicos: sistematização e análise de uma pesquisa empírica de abordagem qualitativa

Esta investigação integra-se às ações de um estágio de pós-doutoramento, cujas atividades iniciaram-se em 15 de abril de 2015 e encerraram-se em abril de 2016, como também ao desenvolvimento de um subprojeto do Programa Institucional de Bolsa de Iniciação da Docência (PIBID), coordenado pela Universidade do Estado de Mato Grosso, Curso de Pedagogia, Câmpus de Juara. Dentre as demais ações voltadas à realização do referido estágio, bem como ao desenvolvimento do subprojeto do PIBID, incluiu-se a pesquisa que investigou as avaliações internas e externas instituídas pela política pública reservada à alfabetização das crianças brasileiras (PNAIC), em Mato Grosso.

A intencionalidade dessa pesquisa adotou a investigação qualitativa. Essa investigação privilegia a empiria, abordagem que exige a justaposição dos pesquisadores com o campo de estudo (MARCONI e LAKATOS, 2002). Assim, as avaliações da aprendizagem alocadas no Simec/SisPacto, foram sistematizadas e analisadas sob influências de um conjunto de ações interativas, estabelecidas entre as pesquisadoras e as equipes da coordenação geral, dos formadores e dos orientadores de 
estudo, instituídas para realizar as ações do PNAIC, como também das coordenadoras de área, supervisores e bolsistas de Iniciação a Docência (IDs) do PIBID. Enquanto profissionais vinculadas às atividades do PNAIC e do PIBID, nos integramos ao universo da pesquisa, interagimos e dialogamos com os demais profissionais também envolvidos com as ações do Pacto em Mato Grosso e do PIBID na UNEMAT, câmpus de Juara. Destacamos essa condição, porque segundo André (1995) as análises das informações empíricas, ao exigir aproximação e interação dos pesquisadores com o objeto em questão pode trazer maior fidedignidade e cientificidade à pesquisa.

Com essa compreensão, as avaliações relativas aos onze direitos de aprendizagem de Língua Portuguesa, disponíveis na Unidade 1 "Currículo na Alfabetização, concepções e princípios (BRASIL, 2012) do PNAIC, alocadas por agrupadores no Simec/SisPacto foram sistematizadas e analisadas. Para sistematizá-las, inicialmente compilamos os onze direitos de aprendizagem de Língua Portuguesa gerais e por ano de escolarização (1으 20 e 3 o ciclos), inseridos pelos alfabetizadores vinculados ao PNAIC no início e no final de 2014. A partir desse compilamento, organizamos as avaliações concernentes a cada um dos onze direitos em quadros que demarcaram como os alfabetizandos se encontravam no início e no final de 2014 , e tecemos as análises nos itens subsequentes.

\section{Os Sistemas de Monitoramentos do Ministério da Educação: Simec/SisPacto}

O Sistema Integrado de Monitoramento Execução e Controle do Ministério da Educação (Simec) é um portal operacional e de gestão do Ministério da Educação (MEC), que trata do orçamento e monitoramento das propostas on-line do governo federal na área da educação. É neste Sistema que os gestores verificam o andamento dos Planos de Ações Articuladas (PAR) em suas cidades $^{1}$.

No Sistema de Monitoramento do Curso de Formação voltado aos Orientadores de Estudo vinculados ao Pacto Nacional pela Alfabetização na Idade Certa (SisPacto), os Coordenadores Locais, os Orientadores de Estudo e os Professores Alfabetizadores inserem dados sobre as ações do PNAIC por eles desencadeadas, em consonância com a função de cada um² ${ }^{2}$ Nos registros sistematizados encontramos inconsistências em relação ao quantitativo de alunos, de professores e de turmas cadastradas no Simec/SisPacto em 2014.

\footnotetext{
1 Informações disponíveis em: http://portal.mec.gov.br/index.php?option=com content\&id=143:simec. Acesso em maio de 2015.

2 Informações disponíveis em: http://pacto.mec.gov.br/31-outros-destaques/79-entenda-o-sispacto. Acesso em: maio de 2015.
} 
Quadro 1: Número de alunos, de professores e de turmas da alfabetização em Mato Grosso: Língua Portuguesa - início e fim/2014.

\begin{tabular}{|l|l|}
\hline Ensino Fundamental - 2014 (início) & Ensino Fundamental - 2014 (fim) \\
\hline № de Alunos: 127.939 & № de Alunos: 99.344 \\
\hline № de Professores: 5.556 & № de Professores: 4.331 \\
\hline № de Turmas: 6.420 & № de Turmas: 4.903 \\
\hline
\end{tabular}

Fonte: Simec.gov.mec.br/sispacto2/sispacto2.php?modulo=relatorio/relatoriospersonalizados\&acao=Acesso em abril de 2015. Adaptado pelas autoras.

Os dados chamam a atenção pela discrepância encontrada entre os números do início e final do ano de 2014. A explicação se encontra, fundamentalmente, na evasão de professores do curso de formação. O próprio Ministério de Educação, por meio do Sispacto, antecipou uma quebra de $20 \%$ no número de professores iniciantes do curso e apresentou o número total para ser atendido (oriundo do censo escolar do ano anterior), e o número menor como sugestão para certificação. 0 principal fato relacionado à desistência dos professores é a saúde, seguido de licença-prêmio.

Esses números abarcam os alunos matriculados nos três primeiros anos da escolarização básica, denominado pelo PNAIC de "Ciclo da Alfabetização". O Simec/SisPacto registrou alunos matriculados no Ensino Fundamental de oito anos (1aㅡ 2a e 3a séries e multi) e no Ensino Fundamental de nove anos (1으, 2을 으 anos e multi).

De acordo com os dados disponibilizados nesses sistemas, no Ensino Fundamental de oito anos, ainda havia em Mato Grosso aproximadamente 10.549 alunos matriculados na 1a série, 7.945 na 2a série, 4.707 na 3a série e 783 em turmas multi, ou seja, 23.984 alunos. Entretanto, a atual Lei de Diretrizes e Bases da Educação Nacional (LDBN, no 9.394/1996), sinalizou a obrigatoriedade da oferta do Ensino Fundamental de nove anos de duração, a iniciar-se aos seis anos de idade. Esta obrigatoriedade tornou-se meta da educação nacional com a Lei no 10.172/2001, que aprovou o Plano Nacional de Educação (PNE). Em 6 de fevereiro de 2006, a Lei no 11.274, institui o Ensino Fundamental de nove anos de duração, com a inclusão das crianças de seis anos de idade na alfabetização.

Esta Lei foi publicada porque várias pesquisas, a exemplo das realizadas pelo Sistema Nacional de Avaliação da Educação Básica (SAEB), informaram que crianças que frequentaram a préescola, obtiveram melhores resultados em proficiência de leitura, nos anos iniciais da Educação Básica, em média 20 pontos a mais do que as demais crianças que não tiveram acesso à Educação Infantil (Pré-escola), (BRASIL, 2007). De acordo com o Art. 5ํํㄹ da referida Lei, os Municípios, os Estados e o Distrito Federal teriam prazo até 2010 para implementar a obrigatoriedade para o Ensino Fundamental de nove anos (Idem). Todavia, em 2014 o Simec/SisPacto publicou que aproximadamente, 23.984 crianças ainda estavam matriculadas no Ensino Fundamental de oito anos, isso apenas no primeiro ciclo (1aㅡ $2^{2}$ a , 3a séries e turmas multi) em Mato Grosso. Esse fato denuncia a 
dificuldade de alguns municípios em acatar as novas determinações legais e reformular os seus sistemas de ensino. No Ensino Fundamental de nove anos, havia em Mato Grosso aproximadamente 33.194 crianças matriculadas no 10 ano, 30.680 no 2 을 ano, 34.446 no 3 o ano e 6.274 em salas multi/anos, ou seja, 104.594 crianças.

3 Os direitos de aprendizagem no ciclo da alfabetização: agrupadores de Língua Portuguesa - início e fim $/ 2014$

A Lei $n$. o 9.394/96 estabelece que as Diretrizes e Bases da Educação Nacional, "têm por finalidades desenvolver o educando, assegurar-Ihe a formação comum indispensável para o exercício da cidadania e fornecer-Ihe meios para progredir no trabalho e em estudos posteriores" (BRASIL, LDB № 9.394, 1996, Art. 22). Nesses termos, a Educação Básica é obrigatória para todos os brasileiros. A sua atribuição social é formar pessoas com autonomia para agir na sociedade e para participar ativamente nas diferentes esferas sociais. Dentre outros direitos, é prioritário o ensino da leitura, da escrita e do cálculo, tal como previsto no Artigo 32 da referida Lei. Em atenção a essa determinação legal, o PNAIC delimitou capacidades e conhecimentos básicos, subjacentes a esses direitos. Alguns desses conhecimentos e capacidades específicos, estão descritos nos quadros que seguem estruturados nesse texto. Eles demonstram, na perspectiva dos professores, a apropriação desses direitos de aprendizagem pelas crianças no início e no final do ano de 2014 , correspondentes aos eixos de ensino de Língua Portuguesa: leitura, produção de textos escritos, oralidade e análise linguística (BRASIL, 2012).

O material do PNAIC dividiu o eixo Análise Linguística em dois quadros: "ensino do Sistema de Escrita Alfabética, necessário para que as crianças tenham autonomia na leitura e produção de textos"; e "análise linguística, fundamental para a ampliação das capacidades para lidar com as situações de produção e compreensão de textos orais e escritos" (BRASIL, 2012, p. 31). Para cada um dos agrupadores organizados nesse texto, o material do PNAIC sugere como o professor deve avaliar a progressão dos referidos conhecimentos ou capacidades durante o ciclo de alfabetização. A letra I indica que "determinado conhecimento ou capacidade deve ser introduzido na etapa escolar indicada; a letra A, que a ação educativa deve garantir o aprofundamento; e a letra C, que a aprendizagem deve ser consolidada no ano indicado" (BRASIL, 2012, p. 33). O material orienta ainda que "determinado conhecimento ou capacidade pode ser introduzido em um ano e aprofundado em anos seguintes. A consolidação também pode ocorrer em mais de um ano escolar, visto que há aprendizagens que exigem um tempo maior para a apropriação" (Idem). Desse modo, os quadros analisados nesse texto, tiveram como referência tal recomendação. 
Quadro 2: Agrupador 1, início e fim/2014

\begin{tabular}{|c|c|c|c|c|c|c|c|}
\hline $\begin{array}{l}\text { Escreve o próprio } \\
\text { nome. }^{3}\end{array}$ & Sim & $\%$ & Parc. & $\%$ & Não & $\%$ & Total \\
\hline Início & 108944 & 85,20 & 14020 & 11,00 & 4975 & 3,90 & 127939 \\
\hline Fim & 93947 & 94,60 & 4015 & 4,00 & 1374 & 1,40 & 99336 \\
\hline
\end{tabular}

Fonte: Idem Quadro 1.

De um universo aproximado de 127.939 crianças matriculadas no início do ano, 18.995 escreviam parcialmente ou não sabiam escrever o próprio nome. No final do ano, embora 93.947 crianças demonstrassem que sabiam escrever o próprio nome, 5.389 permaneceram sem esse direito plenamente construído. Nesse sentido, Teles (2014), afirma que o insuficiente aprendizado das crianças matriculadas em escolas públicas brasileiras, decorre, em parte, da desigualdade e da exclusão social. Contudo, a superação desta realidade demanda enfrentamento "com ações políticas de estado que extrapolem mandatos ou condições econômicas vigentes" (p. 40). Um desses enfrentamentos seria priorizar o acesso de todas as crianças à Educação Infantil e ao Ensino Fundamental de nove anos. Como já afirmamos, quanto mais cedo elas forem encaminhadas às escolas, melhor será o seu desenvolvimento. A maioria das crianças que frequentou a Educação Infantil chegou ao Ciclo da Alfabetização escrevendo o próprio nome. Como afirma Cavalcante (2012), muitas crianças brasileiras não aprendem, "mas não porque não têm condições, e sim porque seus direitos à aprendizagem estão sendo negados" (p. 17), por isso há a necessidade de uma cuidadosa reflexão acerca dessas avaliações.

Quadro 3: Agrupador 2 - início e fim/2014.

\begin{tabular}{|l|l|l|l|l|l|l|c|}
\hline $\begin{array}{l}\text { Reconhece as letras do alfabeto } \\
\text { por seus nomes. }\end{array}$ & $\operatorname{Sim}$ & $\%$ & Parc. & $\%$ & Não & $\%$ & Total \\
\hline Início & 108297 & 84,60 & 13297 & 10,40 & 6345 & 5,00 & 127939 \\
\hline Fim & 93347 & 94,00 & 4259 & 4,30 & 1738 & 1,70 & 99344 \\
\hline
\end{tabular}

Fonte: Idem Quadro 1.

Apesar da importante evolução, no final de 2014, aproximadamente 5.997 crianças tinham dificuldades para reconhecer as letras do alfabeto por seu nome. Assim como o direito de aprender a escrever o próprio nome, reconhecer as letras do alfabeto é um conhecimento que precisa ser introduzido, aprofundado e consolidado no primeiro ano do Ciclo da Alfabetização. Esse conhecimento corresponde ao eixo da Análise Linguística: apropriação do Sistema de Escrita Alfabética (SEA), condição primeira para a apropriação dos demais conhecimentos (BRASIL, 2012).

Quadro 4: Agrupador 3 - início e fim/2014.

3 Devido à discrepância nos números de professores e turmas participantes de início e fim de ano, observar a curva ascendente por meio da porcentagem. 


\begin{tabular}{|l|l|l|l|l|l|l|l|}
\hline $\begin{array}{l}\text { Diferencia letras de números e } \\
\text { outros símbolos. }\end{array}$ & Sim & $\%$ & Parc. & $\%$ & Não & $\%$ & Total \\
\hline Início & 112577 & 88,00 & 9898 & 7,70 & 5443 & 4,30 & 127918 \\
\hline Fim & 94307 & 94,90 & 3500 & 3,50 & 1537 & 1,50 & 99344 \\
\hline
\end{tabular}

Fonte: Idem Quadro 1.

Diferenciar letras de números e outros símbolos é um conhecimento que também precisa ser introduzido, aprofundado e consolidado no primeiro ano do ciclo da alfabetização (BRASIL, 2012). Apesar do importante avanço, em que, aproximadamente, apenas 5\% das crianças ainda não tinham construído esse conhecimento no final de 2014, vale ressaltar que da mesma forma que há conhecimentos que podem ser aprofundados e consolidados em outros anos do ciclo de alfabetização, há conhecimentos que precisam ser consolidados no primeiro ano de escolarização básica, pois são requisitos para que outros conhecimentos sejam construídos. O direito em discussão configura-se como tal, ou seja, é condição para que a alfabetização se efetive no final do 3o ano do ciclo.

Quadro 5: Agrupador 4 - início e fim/2014.

\begin{tabular}{|l|l|l|l|l|l|l|l|}
\hline $\begin{array}{l}\text { Utiliza Letras na escrita das } \\
\text { palavras. }\end{array}$ & Sim & $\%$ & Parc. & $\%$ & Não & $\%$ & Total \\
\hline Início & 110363 & 86,30 & 10843 & 8,50 & 6709 & 5,20 & 127915 \\
\hline Fim & 93347 & 94,00 & 4070 & 4,10 & 1927 & 1,90 & 99344 \\
\hline
\end{tabular}

Fonte: Idem Quadro 1.

Os dados sistematizados mostram considerada evolução. De aproximadamente 17.552 crianças que não utilizavam letras na escrita de palavras no início do ano, 11.555 passaram a utilizar no final no ano. No entanto, 5.997 crianças ainda estavam distanciadas deste direito. As orientações contidas no material do PNAIC, informam que este conhecimento deverá ser introduzido no 1 을, aprofundado e consolidado no 2ㅇa, ano, em último caso, consolidado do 3o ano (BRASIL, 2012). Portanto,

em relação à apropriação da escrita alfabética, espera-se que, no $1^{\circ}$ ano, as práticas de ensino da leitura e da escrita possibilitem à criança a construção da base alfabética e que os 2 ㅇ e 3 o anos sejam destinados à consolidação das correspondências som-grafia por meio de diversas situações significativas e contextualizadas de escrita de palavras e textos (CRUZ e ALBUQUERQUE, 2012, p.16).

Como vemos a construção da base alfabética no primeiro ano da alfabetização é condição para que as crianças consolidem as correspondências grafo-fônicas nos dois últimos anos do ciclo. Mesmo porque, elas têm condições de se apropriarem do SEA no primeiro ano, "ao mesmo tempo 
em que ampliam suas experiências de letramento e concluam os $2^{\circ}$ e 3 anos lendo e produzindo textos de diferentes gêneros de modo mais autônomo" (Idem, p. 16).

Quadro 6: Agrupador 5 - início e fim/2014.

\begin{tabular}{|l|l|l|l|l|l|l|l|}
\hline $\begin{array}{l}\text { Escreve palavras } \\
\text { estabelecendo algumas } \\
\text { correspondências entre } \\
\text { letras e seu valor sonoro, } \\
\text { mesmo omitindo, mudando } \\
\text { a ordem ou trocando as } \\
\text { letras. }\end{array}$ & Sim & $\%$ & Parc. & $\%$ & Não & $\%$ & Total \\
\hline Início & 89945 & 70,30 & 23336 & 18,20 & 14658 & 11,50 & 127939 \\
\hline Fim & 85590 & 86,20 & 9650 & 9,70 & 4104 & 4,10 & 99344 \\
\hline
\end{tabular}

Fonte: Idem Quadro 1.

Em relação a esse direito, a evolução também foi importante. Os dados mostram que aproximadamente 24.240 crianças aprenderam a escrever palavras estabelecendo algumas correspondências entre elas e o seu valor sonoro, mesmo omitindo, mudando a ordem ou trocando as letras. No entanto, aproximadamente 13.754 ainda não tinham se apropriado plenamente do direito. De acordo com as recomendações do PNAIC, esse direito precisa ser consolidado até o final do $2 \circ$ ano do 1으 ciclo (BRASIL, 2012). Como afirmam Cruz e Albuquerque (2012, p.16):

é preciso que os alunos, no final do 20 ano, dominem as correspondências entre letras ou grupos de letras e seu valor sonoro, de modo a ler e escrever palavras formadas por diferentes estruturas silábicas, além de saberem segmentar as palavras na escrita de textos e utilizarem diferentes tipos de letras de acordo com as situações de leitura e produção de textos diversos.

As autoras chamam a atenção para esta apropriação porque nos últimos anos, no Brasil, muitas crianças iniciaram o 20 ano do Ensino Fundamental, sem o domínio do SEA.

Quadro 7: Agrupador 6 - início e fim/2014.

\begin{tabular}{|l|l|l|l|l|l|l|l|}
\hline $\begin{array}{l}\text { Escreve palavras com } \\
\text { diferentes estruturas } \\
\text { silábicas, atendendo a } \\
\text { algumas convenções } \\
\text { ortográficas. }\end{array}$ & Sim & $\%$ & Parc. & $\%$ & Não & $\%$ & Total \\
\hline Início & 74540 & 58,30 & 31372 & 24,50 & 22027 & 17,20 & 127939 \\
\hline Fim & 79379 & 79,90 & 14247 & 14,30 & 5718 & 5,80 & 99344 \\
\hline
\end{tabular}

Fonte: Idem Quadro 1.

No início de 2014, aproximadamente 53.339 crianças escreviam parcialmente ou não escreviam palavras com diferentes estruturas silábicas, atendendo a algumas convenções 
ortográficas. No final do ano esse número caiu para aproximadamente 19.965 crianças. O avanço foi significativo, mas a quantidade de crianças que não construíram o direito é preocupante. De acordo com o quadro de direitos de aprendizagem (BRASIL, 2012, p. 35) esse conhecimento precisa ser introduzido no 1 을 ano do Ciclo da Alfabetização, aprofundado e consolidado no 20 ano, admitindo-se em último caso, a sua consolidação no 3 o ano. Apesar da complexidade do SEA, Cruz e Albuquerque (2012) ressaltam que essa não impede que no "primeiro ano do Ensino Fundamental, as crianças já tenham se apropriado dos conhecimentos acerca do funcionamento" (p. 14) desse Sistema. Para as autoras, crianças alfabéticas "conseguem compreender o sistema notacional e, por isso, são capazes de ler e escrever palavras (ainda que apresentem dificuldades) e, às vezes, frases e pequenos textos" (p. 14). Então, podemos afirmar que aproximadamente 19.965 crianças matriculadas no Ciclo da Alfabetização, no final de 2014, ainda não estavam no nível alfabético. Quantitativo expressivo, se considerarmos que todas as crianças têm o direito de atingir o nível alfabético no final do seu primeiro ano de escolarização básica.

Quadro 8: Agrupador 7 - início e fim/2014.

\begin{tabular}{|l|l|l|l|l|l|l|l|}
\hline $\begin{array}{l}\text { Lê palavras formadas por } \\
\text { diferentes estruturas } \\
\text { silábicas. }\end{array}$ & Sim & $\%$ & Parc. & $\%$ & Não & $\%$ & Total \\
\hline Início & 73723 & 57,60 & 30300 & 27,70 & 23916 & 18,70 & 127939 \\
\hline Fim & 79071 & 79,60 & 14185 & 14,30 & 6088 & 6,10 & 99344 \\
\hline
\end{tabular}

Fonte: Idem Quadro 1.

Em relação a este conhecimento, o quadro informa um significativo avanço das crianças. No entanto, de aproximadamente 54.215 crianças que não liam palavras formadas por diferentes estruturas silábicas no início de 2014, no final do ano permaneceram sem esse conhecimento construído aproximadamente 20.273. O quadro de direitos de aprendizagem (BRASIL, 2012), indica que o conhecimento precisa ser introduzido e aprofundado no 1 을 ano, aprofundado e consolidado no 2o ano.

Quadro 9: Agrupador 8 - início e fim/2014

\begin{tabular}{|l|l|l|l|l|l|l|l|}
\hline $\begin{array}{l}\text { Lê textos de gêneros e } \\
\text { temáticas familiares em voz } \\
\text { alta. }\end{array}$ & Sim & $\%$ & Parc. & $\%$ & Não & $\%$ & Total \\
\hline Início & 62531 & 48,90 & 30853 & 24,10 & 34548 & 27,00 & 127932 \\
\hline Fim & 73338 & 73,80 & 17134 & 17,30 & 8849 & 8,90 & 99321 \\
\hline
\end{tabular}

Fonte: Idem Quadro 1.

Os dados sistematizados indicam que aproximadamente 65.401 crianças matriculadas no ciclo da alfabetização, no início de 2014, liam com dificuldade ou não liam textos de gêneros e 
temáticas familiares em voz alta. No final do referido ano, o percentual de crianças que tinham se apropriado desse direito, saltou de $48,90 \%$ para $73,80 \%$. Apesar do avanço, ainda assim, infelizmente 25.903 crianças permaneceram sem esse direito construído. O quadro de aprendizagem de "Leitura" (BRASIL, 2012, p. 31) destaca que esse conhecimento precisa ser introduzido e aprofundado no 1o ano, aprofundado e consolidado no 20 ano, ou seja, "em relação à capacidade de leitura, espera-se que a criança desenvolva uma leitura fluente e compreensão dos textos lidos com autonomia ao final do 2 o ano" (CRUZ, 2012, p. 22).

Ter acesso ao conhecimento e avançar na aprendizagem é um direito de todos os brasileiros.

Desse modo, o direito ao conhecimento é um compromisso social que deveria garantir que "todas" as crianças estivessem alfabetizadas ao final do 3o ano de escolarização.

Ressaltamos, porém, que a educação inclusiva a que estamos nos referindo é na perspectiva de uma escola justa que possibilite à criança a aprendizagem não só da leitura e da escrita de palavras isoladas, mas da leitura e produção de textos, cumprindo a alfabetização a sua dimensão política e pedagógica, por meio da igualdade de oportunidades, considerando a diversidade de processos de aprendizagem e respeitando a heterogeneidade das turmas (CRUZ, 2012a, p. 06).

Portanto, em que pesem avanços significativos, a dimensão política e pedagógica da alfabetização pode estar sendo negada para mais de $26 \%$ das crianças matriculadas no ciclo da alfabetização em Mato Grosso, o que denota, claramente, a necessidade de continuidade da oferta de formação continuada aos professores alfabetizadores.

Quadro 10: Agrupador 9 - início e fim/2014.

\begin{tabular}{|l|l|l|l|l|l|l|c|}
\hline $\begin{array}{l}\text { Compreende textos de } \\
\text { gêneros, temáticas e } \\
\text { vocabulários familiares. }\end{array}$ & Sim & $\%$ & Parc. & $\%$ & Não & $\%$ & Total \\
\hline Início & 66811 & 52,20 & 33104 & 25,90 & 28024 & 21,90 & 127939 \\
\hline Fim & 74213 & 74,70 & 17401 & 17,50 & 7730 & 7,80 & 99344 \\
\hline
\end{tabular}

Fonte: Idem Quadro 1.

Houve coerência nas avaliações inseridas no Simec/SisPacto em relação a apropriação dos direitos de aprendizagem. O quantitativo de crianças que não liam se aproximava do quantitativo de crianças que não compreendiam textos, temáticas e vocabulários familiares. Para que haja compreensão dos textos, primeiramente é preciso que aconteça uma leitura fluente. Aproximadamente $25 \%$ das crianças não tinham construído esse direito ao final do ano de 2014 . Todavia, o quadro de direitos de aprendizagem de "Leitura" (BRASIL, 2012, p. 31) informa que: "compreender textos lidos por outras pessoas, de diferentes gêneros e com diferentes propósitos" é 
um conhecimento que precisa ser introduzido e aprofundado no $1^{\circ}$ ano, aprofundado e consolidado no 20 e no 3 ㅇ anos do Ciclo da Alfabetização. Portanto,

A razão da ampliação do período de alfabetização para três anos, sem retenção, se justifica pela possibilidade de o ensino propiciar a produção/apropriação da escrita e da leitura baseado nos princípios da continuidade e do aprofundamento. Nesse contexto, a construção/apropriação do conhecimento pelos estudantes se daria em uma progressão durante o período. Tal opção, contudo, não implica deixar de garantir os direitos de aprendizagem necessários a cada ano [...] (CRUZ, 2012a, p. 08).

Contudo, os dados do Simec/SisPacto indicam que Mato Grosso pode ter deixado de assegurar os direitos de aprendizagem necessários a cada ano, para aproximadamente 25.131 crianças em 2014.

Quadro 11: Agrupador 10 - início e fim/2014.

\begin{tabular}{|l|l|l|l|l|l|l|l|}
\hline $\begin{array}{l}\text { Produz textos escritos de } \\
\text { gênero, temática e } \\
\text { vocabulário familiares. }\end{array}$ & Sim & $\%$ & Parc. & $\%$ & Não & $\%$ & Total \\
\hline Início & 52408 & 41,00 & 32438 & 25,40 & 43093 & 33,70 & 127939 \\
\hline Fim & 66661 & 67,10 & 20696 & 20,80 & 11987 & 12,10 & 99344 \\
\hline
\end{tabular}

Fonte: Idem Quadro 1.

O quadro de direitos de aprendizagem de "Produção de textos escritos" (BRASIL, 2012, p. 32) indica que produzir textos escritos de gênero, temática e vocabulário familiares é um conhecimento que precisa ser introduzido no 1 을 ano, aprofundado e consolidado no 2 ano, e consolidado no 3 은 ano. Apesar da considerada evolução, no final do ano de 2014, aproximadamente 32.683 crianças permaneceram com esse direito parcialmente, ou não consolidado. Contudo, para que as crianças tenham autonomia para produzir textos escritos, primeiro elas precisam dominar o SEA e, consequentemente, a leitura.

Segundo Cruz no 2 o ano "a criança já deve estar alfabética para avançar com autonomia na consolidação da capacidade de leitura e escrita de textos para que se torne progressivamente alfabetizada e letrada" (2012, p. 21). Para que isso ocorra, "a escrita de palavras com diversas estruturas silábicas e que contemplem as regras ortográficas regulares diretas e regularidades contextuais" (Idem) precisa ser continuadamente trabalhada e avaliada.

Caso sejam identificadas crianças que não dominem tais conhecimentos, é preciso planejar ações didáticas voltadas a tais objetivos. Em relação à produção textual, espera-se que a criança consolide a capacidade de 
refletir, com crescente autonomia, sobre o contexto de produção de textos, o planejamento da escrita e a produção dos textos para atender a diferentes finalidades bem como sobre a organização do conteúdo textual, a estruturação dos períodos e o uso dos recursos coesivos (CRUZ, 2012, p 22).

Estas recomendações nos levam a inferir que muitos alfabetizadores podem estar negligenciando em relação ao planejamento interventivo. A consequência disso é que muitas crianças não conseguem avançar autonomamente no processo de apropriação da leitura e da escrita e se tornarem progressivamente alfabetizadas e letradas.

Quadro 12: Agrupador 11 - início e fim/2014.

\begin{tabular}{|l|l|l|l|l|l|l|l|}
\hline $\begin{array}{l}\text { Participa de situações } \\
\text { produzindo e } \\
\text { compreendendo textos orais } \\
\text { de gêneros e temas } \\
\text { familiares. }\end{array}$ & Sim & $\%$ & Parc. & $\%$ & Não & $\%$ & Total \\
\hline Início & 71985 & 56,30 & 31010 & 24,20 & 24944 & 19,50 & 127939 \\
\hline Fim & 75171 & 75,70 & 16500 & 10,60 & 7673 & 7,70 & 99344 \\
\hline
\end{tabular}

Fonte: Idem Quadro 1.

De acordo com o eixo "Oralidade" (BRASIL, 2012, p. 33) esse é um conhecimento que precisa ser introduzido no 1 을 ano, aprofundado e consolidado no 20 e no 3 을 ano. Aproximadamente 55.954 crianças matriculadas no ciclo da alfabetização participavam parcialmente, ou não participavam de situações com produção e compreensão de textos orais de gêneros e temas familiares, no início do ano letivo de 2014. No final desse ano, permaneceram com esse conhecimento parcialmente ou não construído, 31.781 crianças. Realidade que nos remete a afirmação de Moreira e Candau (2007), para estas pesquisadoras, o direito do estudante à apropriação do conhecimento precisa ser recuperado.

Apresentamos, a seguir, um quadro síntese das conquistas obtidas ao longo de 2014 em Língua Portuguesa e do desafio que ainda precisa ser enfrentado pelos alfabetizadores:

Quadro 13: Dados Gerais dos Direitos de Aprendizagem em Língua Portuguesa - final de 2014.

\begin{tabular}{|l|l|l|}
\hline Direitos de aprendizagem & Consolidados & A consolidar \\
\hline 1. Escreve o próprio nome. & 93.947 & 5.389 \\
\hline 2. Reconhece as letras do alfabeto por seus nomes. & 93347 & 5997 \\
\hline 3. Diferencia letras de números e outros símbolos. & 94307 & 5037 \\
\hline 4. Utiliza Letras na escrita das palavras. & 93347 & 5997 \\
\hline $\begin{array}{l}\text { 5. Escreve palavras estabelecendo algumas } \\
\text { correspondências entre letras e seu valor sonoro, mesmo } \\
\text { omitindo, mudando a ordem ou trocando as letras. }\end{array}$ & 85590 & 13754 \\
\hline $\begin{array}{l}\text { 6. Escreve palavras com diferentes estruturas silábicas, } \\
\text { atendendo a algumas convenções ortográficas. }\end{array}$ & 79379 & 19965 \\
\hline 7. Lê palavras formadas por diferentes estruturas & 79071 & 20273 \\
\hline
\end{tabular}




\begin{tabular}{|l|l|l|}
\hline silábicas. & & \\
\hline 8. Lê textos de gêneros e temáticas familiares em voz alta. & 73338 & 25983 \\
\hline $\begin{array}{l}\text { 9. Compreende textos de gêneros, temáticas e } \\
\text { vocabulários familiares. }\end{array}$ & 74213 & 251131 \\
\hline $\begin{array}{l}\text { 10. Produz textos escritos de gênero, temática e } \\
\text { vocabulário familiares. }\end{array}$ & 66661 & 32683 \\
\hline $\begin{array}{l}\text { 11. Participa de situações produzindo e compreendendo } \\
\text { textos orais de gêneros e temas familiares. }\end{array}$ & 75171 & 24173 \\
\hline
\end{tabular}

Fonte: Idem Quadro 1.

Segundo Cruz (2012, p. 11) "o ciclo de alfabetização, ao ser concebido como uma etapa escolar de três anos, favorece o estabelecimento de estratégias em que os conhecimentos sejam gradativamente apropriados, por meio de retomadas e aprofundamentos contínuos". Os números indicam, por um lado, importantes conquistas dos alfabetizandos, que pode ter uma correlação positiva com o curso de formação ofertado pelo PNAIC e demais atividades realizadas pelo PIBID, por outro lado, que a apropriação gradativa dos conhecimentos pode não estar acontecendo, na velocidade esperada, em boa parte das turmas do 10 ciclo de escolarização de Mato Grosso, uma vez que o percentual de crianças que não se apropriaram dos direitos de aprendizagem elementares, para avançar do nível alfabético para o nível alfabetizado é expressivo. Porém, ressaltamos que esses números englobam os três primeiros anos do Ensino Fundamental, podendo as lacunas se concentrarem mais fortemente no primeiro e segundo anos.

\section{Considerações Finais}

Quando nos dispomos realizar essa investigação, estávamos cientes de que as avaliações realizadas no interior das salas de aulas de alfabetização de Mato Grosso pelos professores e, posteriormente, inseridas no Simec/SisPacto, de certa forma, condicionavam-se aos agrupadores/direitos de aprendizagem privilegiados pelo referido Sistema e destacados no material do PNAIC. Reconhecemos os limites desse Sistema que não permite uma avaliação mais abrangente. Em nossa compreensão, é muito difícil abarcar todas as dimensões formativas e de aprendizagem em um documento avaliativo, por isso esses serão sempre incompletos e limitados.

Também não podemos descartar que "os valores e as lógicas de avaliação reproduzem os valores, lógicas e hierarquias que selecionam e organizam os conhecimentos nos currículos" (BRASIL, 2007a, p. 13). Neste sentido, o currículo elaborado para o Ciclo da Alfabetização nas escolas públicas brasileiras, privilegia conhecimentos cobrados nas avaliações escolares (internas) e nacionais (externas). Por isso, não podemos desconsiderar toda a carga ideológica e subjetiva desse processo, uma vez que não há neutralidade curricular. Nesses termos, "os conhecimentos escolares tendem a 
se submeter aos ritmos e às rotinas que permitem sua avaliação. Ou seja, tendem a ensinar conhecimentos que possam ser, de algum modo, avaliados" (MOREIRA e CANDAU, 2007, p. 25).

Entretanto, Fernandes e Freitas (2007) afirmam que a avaliação escolar se traduz em uma reflexão constante sobre as informações obtidas por meio de atividades avaliadoras, realizadas continuadamente no decorrer do processo de construção do conhecimento. Com esta compreensão, tecemos algumas reflexões acerca do resultado das avaliações disponibilizadas no Simec/SisPacto pelos professores do Ciclo da Alfabetização, no início e no final de 2014.

As informações inseridas no referido Sistema indicam um processo evolutivo coerente dos alfabetizandos em relação aos agrupadores/direitos de aprendizagem, como também uma correlação deste processo evolutivo entre um e outro direito. Mesmo assim, os dados referentes aos conhecimentos alfabetizadores denotam que considerável número de crianças matriculadas no Ciclo da Alfabetização conclui essa importante etapa escolar sem a devida apropriação do SEA. É preocupante a quantidade de crianças que, por não terem dominado esse sistema, apresentam dificuldades na leitura e na interpretação de textos de diferentes gêneros. A não apropriação do SEA impede as crianças de escrever, produzir textos, ler e interpretar convencionalmente.

As informações indicam a urgente necessidade de repensar o trabalho realizado no interior das salas de aulas do Ciclo de Alfabetização em atenção à superação das fragilidades decorrentes desse processo. Ao mesmo tempo em que defendemos que todas as crianças têm o direito de se apropriarem do SEA até aos oito anos de idade, pois esta apropriação é condição para a continuidade do processo de aprendizagem, não podemos desconsiderar a heterogeneidade existente no interior das salas de alfabetização. Isto implica compreender que os alfabetizandos estão em diferentes estágios de desenvolvimento, mas não estão impedidos de aprender. Os tempos de aprendizagem não são homogêneos, porém a função social da escola é promover o desenvolvimento cognitivo e o crescimento humano, social, político e cultural de todos. Nesse sentido, o PNAIC considera os três primeiros anos do Ensino Fundamental, o Ciclo da Alfabetização. Tempo que julgamos ser suficiente para a consolidação da apropriação do SEA, apesar de toda a diversidade social, cultural e étnica acolhida pelas escolas públicas brasileiras.

A tarefa é complexa, impõem esforços conjuntos, compromisso e respeito particulares aos seres humanos. O afastamento dos alfabetizandos da apropriação do SEA os distanciará do acesso aos conhecimentos historicamente e culturalmente construídos. Desse modo, a escola continuará promovendo a exclusão de importante demanda educativa. Entretanto, lembramos que:

muito do que o professor consegue ou não em seu local de trabalho depende de fatores que estão presentes no âmbito da escola e do sistema de ensino. Tais fatores ou facilitadores precisam igualmente ser avaliados como parte integrante da explicação das conquistas e fracassos que possam 
ocorrer no âmbito da sala de aula. Esses outros espaços possuem seus próprios procedimentos de avaliação (FERNANDES e FREITAS, 2007, p. 38).

Portanto, a complexa organização escolar, com seus múltiplos atores e interesses, não pode ignorar os indicadores avaliativos apresentados. A avaliação escolar é uma necessidade, com vistas a promover a inclusão de todos os seres humanos. Os dados indicam fragilidades que o coletivo escolar precisa analisar reflexivamente, para posteriores proposições de superação dos problemas que impedem a alfabetização das crianças. As escolas de Mato Grosso precisam caminhar para a democratização educacional e superar a dualidade que essas tendem em conservar. Em nossa compreensão, é preciso driblar o sistema e aproveitar todas as possibilidades para que as crianças se apropriem do SEA no ciclo da alfabetização. A partir do momento que a criança tem o domínio sobre a leitura, a interpretação, a produção escrita e a oralidade, as barreiras voltadas à aprendizagem serão gradativamente vencidas, em todas as áreas do conhecimento. Todavia, ressaltamos que a apropriação do SEA é condição para que as demais alfabetizações aconteçam: matemática, estatística, geográfica, cartográfica, histórica, tecnológica, dentre outras, necessárias para o pleno exercício da cidadania.

Nesse sentido, o resultado dessa análise confere a relevância do PNAIC e do PIBID, bem como suas continuidades, pois a formação inicial articulada à formação continuada, ainda é a via mais importante que poderá, em longo prazo, trazer resultados importantes no avanço da qualidade social da educação ofertada.

\title{
PORTUGUESE LANGUAGE EVALUATIONS IN THE CONTEXT OF THE NATIONAL COVENANT FOR LITERACY IN THE RIGHT AGE IN MATO GROSSO
}

\begin{abstract}
The article analyzes the Portuguese language assessments inserted in Simec/SisPacto by teachers of Mato Grosso, at the beginning and end of 2014. The assessments refer to the eleven rights of Portuguese Language learning and have been awarded for the overall coordination of PNAIC in Mato Grosso in April 2015. These were systematized in tables and demonstrate how learners were at the beginning and end of 2014, in relation to each of the learning rights. The analysis was anchored in the qualitative approach and investigated if there was an advance in the appropriation of the knowledge of the literacy students and a correlation between the learning rights. The weaknesses of the literacy process were pointed out and adjustments needed to overcome these were indicated.
\end{abstract}

Keywords: Literacy. Evaluation. Mato Grosso. 
Referências

ANDRÉ, Marli Eliza Dalmazo Afonso de. Etnografia da prática escolar. SP, Campinas: Papirus, 1995.

BRASIL, Ministério da Educação, Secretaria de Educação Básica. Ensino Fundamental de nove anos: orientações para a inclusão da criança de seis anos de idade. Organização: Janete Beauchamp, Sandra Denise Pagel e Aricélia Ribeiro do Nascimento. Brasília: 2007, 135 p.:il.

BRASIL, Ministério da Educação, Secretaria de Educação Básica. Indagações sobre currículo. (Orgs.) BEAUCHAMP, Janete et al. Brasília, 2007a. Disponível em: http://portal. mec.gov.br/seb/arquivos/pdf/Ensfund/indag3.pdf.

BRASIL, Ministério da Educação. Secretaria de Educação Básica. Diretoria de Apoio a Gestão Educacional. Pacto Nacional Pela Alfabetização na Idade Certa. Avaliação no ciclo da alfabetização: reflexões e sugestões. Brasília: 2012.

BRASIL, Secretaria de Educação Básica. Diretoria de Apoio à Gestão Educacional. Pacto Nacional pela Alfabetização na Idade Certa: Currículo na Alfabetização: concepções e princípios. Ano 01, Unidade 01. Brasília: MEC, SEB, 2012a.

CAVALCANTE, Tícia Cassiany Ferro. Pensando a alfabetização da pessoa com deficiência intelectual. In.: BRASIL, Secretaria de Educação Básica. Diretoria de Apoio à Gestão Educacional. Pacto Nacional pela Alfabetização na Idade Certa: Caderno de Educação Especial. A alfabetização de crianças com deficiência: uma proposta inclusiva. Brasília: MEC, SEB, 2012.

CRUZ, Magna do Carmo Silva e ALBUQUerque Eliana Borges Correia de. A complexidade da aprendizagem do Sistema de Escrita Alfabética: ampliação do tempo para a consolidação da leitura e da escrita pela criança. In.: BRASIL, Secretaria de Educação Básica. Diretoria de Apoio à Gestão Educacional. Pacto Nacional pela Alfabetização na Idade Certa: Currículo na Alfabetização: consolidação e monitoramento do processo de aprendizagem. Ano 02, unidade 01. Brasília: MEC, SEB, 2012.

CRUZ, Magna do Carmo Silva. Avaliação no ciclo de alfabetização: o monitoramento do processo de ensino e de aprendizagem das crianças. In.: BRASIL, Secretaria de Educação Básica. Diretoria de Apoio à Gestão Educacional. Pacto Nacional pela Alfabetização na Idade Certa: Currículo na Alfabetização: consolidação e monitoramento do processo de aprendizagem. Ano 02, Unidade 01. Brasília: MEC, SEB, 2012.

CRUZ, Magna do Carmo Silva. Currículo no ciclo de alfabetização: ampliando o direito de aprendizagem a todas as crianças. In.: BRASIL, Secretaria de Educação Básica. Diretoria de Apoio à Gestão Educacional. Pacto Nacional pela Alfabetização na Idade Certa: Currículo na Alfabetização: consolidação e monitoramento do processo de aprendizagem. Ano 02, Unidade 01. Brasília: MEC, SEB, 2012a.

FERNANDES, Claudia de Oliveira e FREITAS, Luiz Carlos de. Currículo e Avalição. In.: BRASIL, Ministério da Educação, Secretaria de Educação Básica. Indagações sobre currículo: currículo e avaliação. (Orgs.) BEAUCHAMP, Janete et al. Brasília, 2007. Disponível em: http://portal.mec.gov.br/seb/ arquivos/pdf/Ensfund/indag3.pdf.

MARCONI, Marina de Andrade; LAKATOS, Eva Maria. Técnicas de Pesquisa: planejamento e execução de pesquisas, amostragens e técnicas de pesquisas, elaboração, análise e interpretação de dados. 5. ed. São Paulo: Atlas, 2002. 
MOREIRA, Flávio Barbosa; CANDAU, Vera Maria. Currículo, conhecimento e cultura. In: BRASIL, Ministério da Educação, Secretaria de Educação Básica. Indagações sobre currículo. (Orgs.) BEAUCHAMP, Janete et al. Brasília, 2007. Disponível em: http://portal. MEC.gov.br/seb/ arquivos/pdf/Ensfund/indag3.pdf. Acesso em 10 de abril, 2016.

TELES, Rosinalda Aurora de Melo. Direitos e objetivos de aprendizagem e desenvolvimento: a Matemática como instrumento de formação e promoção humana. In.: BRASIL, Secretaria de Educação Básica. Diretoria de Apoio à Gestão Educacional. Pacto Nacional pela Alfabetização na Idade Certa: Apresentação, Alfabetização Matemática. Brasília: MEC, SEB, 2014. 